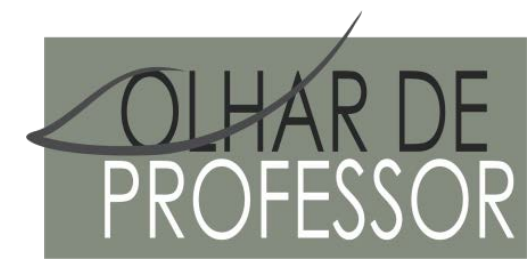

DOl: 10.5212/OLHARPROFR.V.2111.0011

\title{
ENSINO TRADICIONAL OU POR INVESTIGAÇÃO: PERCEPÇÃO DE PROFESSORES ACERCA DE SUA PRÁTICA
}

\author{
TRADITIONAL OR INQUIRY TEACHING: TEACHERS' PERCEPTION OF THEIR PRACTICE \\ ENSEÑANZA TRADICIONAL O POR INVESTIGACIÓN: PERCEPCIÓN DE LOS PROFESSORES SOBRE SU \\ PRÁCTICA
}

\author{
LÍLIA DO ESPÍRITO SANTO AZEVEDO* \\ VALÉRIA DE SOUZA MARCELINO*
}

\begin{abstract}
Resumo: Este artigo é parte do trabalho de conclusão de curso intitulado de " $\mathrm{O}$ ensino investigativo por meio das SEIs: um desafio na prática docente” e teve por objetivo apresentar a análise e discussãode três aspectos dos resultados coletados durante os minicursos, oriundos de questionamentos quanto i) aos conhecimentos prévios dos participantes em relação ao ensino investigativo e, especificamente às SEIs (Sequências de Ensino Investigativo); ii) quanto às características de um ensino adequado na opinião dos participantes; iii) o questionamento à possível utilização das SEIs em aulas ministradas futuramente pelos próprios participantes.A pesquisa consistiu na elaboração e aplicação de um minicurso denominado de "Sequências de Ensino Investigativas" em dois momentos distintos. A aplicação do mesmo foi dividida em seis etapas, totalizando um período de quatro horas e, contou com um total de 49 participantes, sendo estes professores em formação inicial ou continuada. Os resultados obtidos no questionário preliminar demonstraram as diferenças existentes entre os participantes dos dois minicursos quanto aos conhecimentos prévios que os mesmos traziam acerca do assunto que foi trabalhado ao longo da aplicação deste. No questionário final cerca de 98\% dos participantes afirmaram que tinham interesse de utilizar as SEIs em suas aulas. Diante dos resultados obtidos, pôde-se constatar que as quatro horas utilizadas no minicurso foram suficientes para iniciar uma discussão sobre o modelo de ensino tradicional e apresentar a SEI dentro dos parâmetros do modelo de ensino desejável, trazendo desta forma uma contribuição positiva na formação inicial e continuada dos professores participantes.
\end{abstract}

Palavras-chave: Minicurso. Formação inicial e continuada. Ensino por investigação. Sequências de ensino investigativas.

Abstract: This article is part of a course conclusion monograph entitled "Inquiry teaching through IBT: a challenge in teaching practice" and aimed to present the analysis and discussion about three results' aspects collected during mini-courses, arising from questions about i) the participants' previous knowledge regarding investigative teaching and, specifically, the IBT (Inquiry-based teaching); (ii) the characteristics of appropriate teaching in the opinion of the participants; iii) the questioning about possible use of IBT in classes given in the future by the participants themselves. The research consisted of the elaboration and application of a mini-course

\footnotetext{
** Graduada em Ciências da Natureza: Licenciatura em Química pelo Instituto Federal Fluminense - IFF. E-mail: liliaesazevedo@gmail.com

** Doutora em Ensino de Ciências pela Universidade Estadual do Norte Fluminense. Professora titular do Instituto Federal Fluminense. Integrante do Grupo de Pesquisa.”NESAE” (IFF). E-mail: vmarcelino67@gmail.com
} 
denominated "Inquiry Teaching Sequences" in two different moments. Its application was divided into six stages, totaling a period of four hours and had a total of 49 participants, which were teachers in initial or continuing training. The results obtained in the preliminary questionnaire showed the differences between the participants of the two mini-courses regarding their previous knowledge about the subject that was worked on during the application of this mini - course. In the final questionnaire, about $98 \%$ of participants stated that they had an interest in using the IBT in their classes. In face of the results obtained, it was possible to verify that the four hours used in the mini-course were sufficient to initiate a discussion about the traditional teaching model and to present the IBT within the parameters of the desirable teaching model, thus bringing a positive contribution in the initial and continuing training of the participating teachers.

Keywords: Mini-course. Initial and continuing training. Inquiry Teaching. Inquiry Based Teaching.

Resumen: Este artículo es parte del trabajo de conclusión de curso titulado "La enseñanza investigativa a través de las SEIs: un desafío en la práctica docente" y tuvo por objetivo presentar el análisis y discusión de tres aspectos de los resultados recogidos durante los mini cursos, oriundos de cuestionamientos, i) los conocimientos previos de los participantes en relación con la enseñanza de investigación y, en particular, las SEI (Secuencias de Enseñanza Investigativa); ii) en cuanto a las características de una enseñanza adecuada en opinión de los participantes; iii) el cuestionamiento a la posible utilización de las SEIs en las clases impartidas en el futuro por los propios participantes. La investigación consistió en la elaboración y aplicación de un mini curso denominado "Secuencias de Enseñanza Investigativa" en dos momentos distintos. La aplicación del mismo fue dividida en seis etapas, totalizando un período de cuatro horas y, contó con un total de 49 participantes, siendo estos profesores en formación inicial o continuada. Los resultados obtenidos en el cuestionario preliminar demostraron las diferencias existentes entre los participantes de los dos mini cursos en cuanto a los conocimientos previos que los mismos traían acerca del asunto que fue trabajado a lo largo de la aplicación de ese. En el cuestionario final cerca del $98 \%$ de los participantes afirmaron que tenían interés en utilizar las SEIs en sus clases. Ante los resultados obtenidos, se pudo constatar que las cuatro horas utilizadas en el mini curso fueron suficientes para iniciar una discusión sobre el modelo de enseñanza tradicional y presentar la SEI dentro de los parámetros del modelo de enseñanza deseable, trayendo de esta forma una contribución positiva en la formación inicial y continuada de los profesores participantes.

Palabras Clave: Mini curso. Formación inicial y continuada. Enseñanza por Investigación. Secuencias de Enseñanza Investigativa.

\section{INTRODUÇ̃̃O}

Mudanças no cenário educacional tem sido tema de diversas pesquisas, todavia é primordial ressaltar o papel dos professores como principais atores deste cenário. Desta forma, é necessário compreender o docente como uma peça fundamental no processo de contínua transformação educacional. (GUIMARÃES; ECHEVERRÍA; MORAES, 2006).

Este artigo apresenta parte de um trabalho de conclusão de curso desenvolvido no âmbito da formação docente e intitulado de "O ensino investigativo por meio das SEIs: um desafio na prática docente". Um dos objetivos deste trabalho foi analisar os impactos produzidos pela ministração de dois minicursos, quanto à reflexão crítica de professores atuantes e professores ainda em formação inicial, sobre caráter tradicional da prática docente, dominante no ensino atual. (SOLÍS et al., 2012). Além disso, foi apresentado aos participantes uma metodologia de ensino condizente com o modelo investigativo, considerado o modelo de ensino desejável. (GARCIA; PORLÁN, 2000): as Sequências de Ensino Investigativas (SEIs), com intuito de que os mesmos pudessem adotá-la em suas aulas. O minicurso foi ofertado para um total de 49 professores em formação inicial ou continuada.

O objetivo deste artigo é apresentar a análise e discussão de três aspectos dos resultados coletados durante os minicursos, oriundos de questionamentos quanto i) aos conhecimentos prévios 
dos participantes em relação ao ensino investigativo e, especificamente às SEIs; ii) quanto às características de um ensino adequado na opinião dos participantes; e iii) o questionamento à possível utilização das SEIs em aulas ministradas futuramente pelos próprios participantes. Para isto, foi realizada coleta de dados por meio da aplicação de dois questionários: preliminar e final. O questionário preliminar possuía questões abertas e fechadas e, o final, apenas questões abertas. A análise das respostas foi qualitativa e se valeu do referencial teórico adotado, o qual aborda a formação docente, o Ensino por Investigação e, especificamente, as SEIs.

\section{A IMPORTÂNCIA DA FORMAÇÃO DE PROFESSORES NO SENTIDO DA PROMOÇ̄̃O DE MUDANÇAS NO MODELO DE ENSINO VIGENTE}

As mudanças sociais e científicas ocorridas ao longo do século XX levaram os professores a uma corrida incessante na busca de novas formas de ensinar. (IMBERNÓN, 2016). Nesta perspectiva, a formação docente tem sido encarada como um grande desafio devido a constante mudança dos conhecimentos ensinados em sala de aula. (GATTI, 2016).

Com o desgaste do modelo de ensino tradicional que é baseado na transmissão de conhecimentos por parte dos professores e passiva recepção dos mesmos por parte doas alunos, foram surgindo uma série de tentativas de atribuir ao estudante um papel mais ativo na sua aprendizagem. (ALBERGARIA, 2010).

De acordo com Maldaner (2003) é preciso repensar a atividade pedagógica de modo que os alunos tenham a capacidade de não só compreender o mundo em que vivem, mas também de transformá-lo. Nesse contexto, os professores são os únicos profissionais da educação capazes de modificar o modelo de ensino vigente atualmente. (PORLÁN; RIVERO, 1998).

Para Imbernón (2009) "a formação inicial de professores se caracteriza como processo de construção da significação da profissão docente, pois representa a socialização profissional, atribuindo o conhecimento básico ao futuro professor.” Sendo assim, esta formação é essencial para atuação em sala de aula. Por outro lado, a formação continuada assumiu um grande significado na atividade docente para melhoria e constante atualização da profissão diante das inúmeras transformações observadas em diversos âmbitos da sociedade. (IMBERNÓN, 2016).

A formação docente se mostra como o caminho a seguir na busca da qualidade do processo de ensino e aprendizagem, pois, como dito acima, esses profissionais são os responsáveis diretos pelas transformações almejadas e necessárias na educação a nível das atividades desenvolvidas em sala de aula. (GUIMARÃES et al., 2006 apud DELIZOICOV; ANGOTTI; PERNAMBUCO, 2007).

É certo que os docentes precisam ter na formação inicial e na formação continuada aporte teórico para o desenvolvimento de práticas pedagógicas condizentes com as necessidades de um indivíduo inserido na sociedade atual. O estudante, para atuar como cidadão consciente e crítico, precisa saber utilizar os conhecimentos vistos em sala de aula para resolução de problemas presentes em seu cotidiano. Neste contexto, o "Ensino por Investigação", que é uma metodologia de ensino que visa auxiliar o professor na elaboração de aulas voltadas para formação de estudantes/cidadãos ativos no processo de tomada de decisões, foi apresentada e discutida no decorrer dos minicursos, com o intuito de fazer com os professores tomassem consciência de seus respectivos papéis dentro dessa metodologia e a consequente contribuição na formação científica e intelectual de seus alunos.

\section{AS CARACTERÍSTICAS DO ENSINO POR INVESTIGAÇÃO E O PAPEL DO PROFESSOR NESTE MODELO DE ENSINO}

O Ensino por Investigação se caracteriza como uma abordagem didática capaz de englobar distintas estratégias de ensino, entre as mais tradicionais e as mais inovadoras, mas com a finalidade de modificar o papel do aluno, que até então se resumia em ouvir e copiar passivamente o conteúdo transmitido pelo professor. (SASSERON, s. d.). 
O método de Ensino por Investigação se baseia em uma problematização inicial que envolve adversidades presentes na vida cotidiana dos aprendizes, levando-os a uma melhor compreensão do problema, para que sejam capazes de desenvolver pensamento crítico. Desta forma estarão aptos a buscar transformações e soluções conscientes. A investigação não envolve apenas conceitos, mas também debates, reflexões e tomadas de atitude (SASSERON; MACHADO, 2017).

Ensinar a resolver problemas não consiste somente em dotar os alunos de habilidades e estratégias eficazes, mas também em criar neles o hábito e a atividade de enfrentar a aprendizagem como um problema para o qual deve ser encontrada uma resposta. Não é uma questão de somente ensinar a resolver problemas, mas também e ensinar a propor problemas para si mesmo, a transformar a realidade em um problema que mereça ser questionado e estudado. (ECHEVERRÍA; POZO, 1998, p. 14).

Nesta perspectiva, o professor que traz para a sua prática docente uma atividade investigativa, além de dominar o conteúdo que está sendo trabalhado, deve assumir um papel de questionador, argumentando, conduzindo perguntas, propondo desafios e estimulando o desenvolvimento intelectual dos alunos. Desta forma, é possível perceber uma mudança em sua função, que vai de um mero transmissor à orientador do processo de ensino. (AZEVEDO, 2004).

O professor no ensino por investigação é um inovador. Isso não quer dizer que os conceitos trabalhados em sala de aula precisam ser alterados, ainda que possam depender da atualidade do currículo. A grande mudança no papel do professor no ensino por investigação é ser o promotor de oportunidades para novas interações entre os alunos e o conhecimento. (SASSERON, s. d. p. 122).

Enquanto mediador pedagógico, o professor tem a função de facilitar, incentivar e motivar a aprendizagem, se colocando como uma ponte entre o estudante e sua aprendizagem. A forma com que o docente trabalha determinado conteúdo ou tema é que facilitará a produção de conhecimento por parte dos aprendizes, possibilitando a estes a compreensão do mundo ao seu redor e uma eventual interferência no mesmo. (MASETTO, 2000).

O ambiente criado pela abordagem de ensino investigativa é favorável a discussões e apresentação de ideias, permitindo que o aluno desempenhe um papel ativo na construção do seu conhecimento. A investigação se dá a partir do momento em que as informações, posicionamentos particulares e interpretações distintas estão em jogo. Nesse meio, o professor como fomentador da discussão deve contribuir para o surgimento de opiniões distintas e discordantes em relação à situaçãoproblema apresentada, com o cuidado para não criar apatia entre os alunos, mas valorizar o pensamento individual. (SASSERON, s.d.).

[...] Só criando situações de conflito, desnudando e contrapondo os interesses em jogo, sem usar a autoridade para impor opiniões, o professor ajudará a formar cidadãos que possam decidir sobre si próprios, que empreendam ações em busca do bem comum e da consecução das mudanças que considerarem necessárias. Parte crucial desse processo é o desenvolvimento da capacidade de argumentação, que envolve sinceridade e competência no desejo de conhecer e de ouvir outros que possam ter razões que nos façam mudar de idéia. (KRASILCHIK, 1988, p. 60).

Em suma, o modelo de ensino por investigação não traz mudanças no que diz respeito às atividades executadas em sala de aula. A sua grande inovação corresponde a forma com que o professor desempenha sua função, sendo agora orientador e mediador do trabalho, passando para os alunos o papel central em seus respectivos processos de aprendizagem. (SASSERON, s. d.). 


\section{SEQUENCIAS DE ENSINO INVESTIGATIVAS (SEIS): UMA METODOLOGIA DE ENSINO CONDIZENTE COM O ENSINO POR INVESTIGAÇÃO}

As SEIs foram descritas por Carvalho no livro "Ensino de Ciências por Investigação: condições para implementação em sala de aula”, publicado no ano de 2013. Essa metodologia de ensino consiste em uma sequência de quatro atividades-chave específicas: o problema; a sistematização do conhecimento; a contextualização social do conhecimento; e, a atividade de avaliação.

O intuito principal das SEIs é a promoção de um ambiente investigativo para que os alunos sejam conduzidos a um processo simplificado do trabalho científico, de tal modo que estes possam a cada aula ampliar sua cultura científica. (CARVALHO, 2013, p. 9). A aquisição de uma cultura científica não corresponde a preparação dos alunos para que estes pensem ou se comportem como cientistas. O que se propõe é que os estudantes tenham os conhecimentos científicos básicos e, de posse destes, saibam se posicionar frente a problemas de caráter científico. (SASSERON; CARVALHO, 2008). Abaixo, as atividades-chave que compõem a SEI serão apresentadas e brevemente discutidas.

\section{OPROBLEMA}

O problema escolhido para iniciar uma SEI pode variar entre problemas experimentais, problemas não experimentais ou demonstrações investigativas. Normalmente as demonstrações investigativas são utilizadas quando os experimentos escolhidos apresentam algum tipo de risco aos estudantes e, por isso, precisam ser manipulados pelo professor e apenas observado pelos alunos. (CARVALHO, 2013, p. 10). Independentemente do tipo de problema escolhido para introduzir a SEI, todos devem conter as mesmas etapas: discussão em grupos pequenos de alunos, abertura das discussões com toda a classe com a coordenação do professor, e a elaboração individual de um pequeno texto pelos alunos. (CARVALHO, 2013, p. 10-13).

Nessa mesma perspectiva, Azevedo (2004, p. 35) afirma que uma atividade de investigação deve estar apoiada em um contexto problematizador:

Uma atividade de investigação deve partir de uma situação problematizadora e deve levar o aluno a refletir, discutir, explicar, relatar, enfim, que ele comece a produzir seu próprio conhecimento por meio da interação entre o pensar, sentir e fazer. Nessa perspectiva, a aprendizagem de procedimentos e atitudes se torna, dentro do processo de aprendizagem, tão importante quanto a aprendizagem de conceitos e/ou conteúdos. (AZEVEDO, 2004, p. 35).

\section{SISTEMATIZAÇÃO DO CONHECIMENTO}

O objetivo dessa etapa é fazer com que os estudantes reflitam sobre o passo a passo realizado até se chegar à resolução da questão, além de rever os conceitos introduzidos pela problematização inicial. O ideal é que seja fornecido um texto de sistematização para que os alunos tenham acesso ao processo de resolução do problema e à sua solução final numa linguagem mais científica. Essa atividade de leitura do texto de sistematização deve vir acompanhada a uma discussão. O professor tem o papel de conduzir a discussão de modo que os alunos construam o saber científico respectivo ao tema abordado. (CARVALHO, 2013, p. 15). 


\section{CONTEXTUALIZAÇÃO SOCIAL DO CONHECIMENTO}

O intuito desta etapa da SEI é proporcionar aos alunos uma reflexão a respeito de onde aquele determinado conteúdo estudado pode ser visualizado e aplicado em seu dia a dia. Ela pode serrealizada de forma simples, apenas por meio de perguntas, indagações sobre a existência do fenômeno estudado no cotidiano, ou por meio de um texto, quando se pretende obter uma contextualização mais elaborada e/ou aprofundamento do conteúdo. (CARVALHO, 2013, p. 16).

\section{ATIVIDADE DE AVALIAÇÃO}

Carvalho 2013, p. 18-19, sugere que ao término de uma SEI, seja realizada uma avaliação. No entanto, a autora destaca que é interessante que a forma de avaliação seja compatível com a metodologia de ensino utilizada. Para isso, faz-se necessário a mudança de postura do professor em relação ao método tradicional de avaliação. A avaliação contará com a observação e registro das ações realizadas e dos resultados obtidos pela turma e por cada aluno individualmente. Nas SEIs os conteúdos processuais e atitudinais são avaliados, visto que os processos e atitudes fazem parte dessa metodologia.

Assim temos de compatibilizar os objetivos do ensino, realizado pelas atividades das SEIs, com a avaliação da aprendizagem dos alunos nos mesmos termos: avaliação dos conceitos, termos e noções científicas, avaliação das ações e processos da ciência e avaliações das atitudes exibidas durante as atividades de ensino. (CARVALHO, 2013, p.18).

A proposta para avaliação visando a aferição da aprendizagem conceitual é que seja feita em forma de questionamento, construção de painel ou resposta às cruzadinhas, por exemplo. A ideia é que a avaliação se dê de forma interessante, sem que os alunos percebam que estão sendo avaliados. Uma outra forma de avaliação, porém um pouco tradicional seria, ao findar de cada SEI, propor um questionário envolvendo os principais conceitos estudados. (CARVALHO, 2013, p. 18-19).

\section{PERCURSO METODOLÓGICO}

A pesquisa desenvolvida neste trabalho teve uma abordagem qualitativa. As pesquisas de cunho qualitativo preocupam-se com aspectos da realidade que não são possíveis de serem quantificados, visto que estão voltados para a compreensão e interpretação das relações sociais, não se atendo, portanto, a representatividades numéricas (GERHARDT; SILVEIRA, 2009). O papel do pesquisador neste caso é buscar explicações para o porquê das coisas, atuando como um observador atento que documenta, faz registros e anotações. Nesse tipo de pesquisa a discussão dos resultados se dá de forma descritiva e detalhada por meio da utilização de transcrições e comentários interpretativos. (MOREIRA, 2009).

A pesquisa consistiu na elaboração e aplicação de um minicurso denominado de "Sequências de Ensino Investigativas”. O minicurso foi aplicado em dois momentos distintos contando com a participação de professores em formação inicial e continuada. A primeira aplicação foi voltada para alunos de licenciatura em Ciências da Natureza e áreas afins, com poucas exceções, ou seja, sendo a grande maioria ainda em formação inicial. Enquanto que o segundo minicurso foi destinado a servidores de uma Instituição Ensino Superior, estudantes de graduação e pós graduação, bem como docentes da rede municipal e estadual de ensino correspondente a cidade em que foi aplicado. Sendo assim, o público neste segundo minicurso foi diferenciado, visto que contou com a participação de pessoas integrantes de áreas distintas do conhecimento. 
A aplicação de cada minicurso percorreu seis etapas, com um período total de quatro horas. No quadro abaixo estão descritas as etapas do minicurso, bem como o objetivo de cada uma delas. Os procedimentos e resultados obtidos nas etapas 4 e 5 não serão evidenciados e discutidos neste artigo.

Quadro 1 - Estrutura geral do MC

\begin{tabular}{|c|c|c|}
\hline \multicolumn{3}{|c|}{ Estrutura do MC } \\
\hline Etapas & Descrição & Objetivo \\
\hline 1 & $\begin{array}{l}\text { Aplicação de questionário preliminar e } \\
\text { distribuição do material de apoio. }\end{array}$ & $\begin{array}{l}\text { Conhecer o perfil dos participantes e seus } \\
\text { conhecimentos prévios relacionados ao } \\
\text { assunto do Curso e, fornecer um material } \\
\text { condizente com o assunto abordado no } \\
\text { Curso para consulta durante e/ou após o } \\
\text { mesmo. }\end{array}$ \\
\hline 2 & $\begin{array}{c}\text { Reflexão crítica acerca da predominância do } \\
\text { ensino tradicional na escola de hoje, discutindo } \\
\text { a necessidade de superá-lo. }\end{array}$ & $\begin{array}{c}\text { Despertar os participantes para a realidade } \\
\text { do ensino no Brasil. }\end{array}$ \\
\hline 3 & Apresentação das SEIs & $\begin{array}{c}\text { Apresentar uma metodologia de ensino } \\
\text { diferenciada, apta a ser trabalhada pelo } \\
\text { professor em sala de aula com o intuito de } \\
\text { promover a AC dos estudantes. }\end{array}$ \\
\hline 4 & $\begin{array}{c}\text { Divisão dos participantes em grupos para que } \\
\text { elaboração de uma SD seguindo a proposta das } \\
\text { SEIs. }\end{array}$ & $\begin{array}{c}\text { Possibilitar um momento prático para } \\
\text { elaboração de uma SEI e esclarecimento de } \\
\text { eventuais dúvidas. }\end{array}$ \\
\hline 5 & $\begin{array}{c}\text { Exposição sucinta e breve da SEI elaborada por } \\
\text { cada grupo. }\end{array}$ & $\begin{array}{c}\text { Permitir que os participantes conheçam as } \\
\text { propostas de SEI elaboradas por cada grupo. }\end{array}$ \\
\hline 6 & Aplicação de questionário final. & $\begin{array}{l}\text { Questionar os participantes a respeito da } \\
\text { utilização das SEIs em aulas e conhecer suas } \\
\text { respectivas opiniões a respeito do Curso. }\end{array}$ \\
\hline
\end{tabular}

Fonte: Elaboração própria

Na primeira etapa, foi passado o questionário preliminar com intuito de conhecer o perfil dos participantes e seus conhecimentos prévios acerca do assunto abordado. A segunda etapa consistiu em uma reflexão sobre o ensino utilizado na escola de ontem que se perdura na escola de hoje mesmo apesar de tantas inovações tecnológicas, e a necessidade de superá-lo, para que objetivo do ensino de hoje seja formar cidadãos críticos, alfabetizados cientificamente, com a capacidade de opinar acerca de questões científicas que os circundam em seu dia a dia. Esta etapa contou com uma apresentação em slides contendo imagens ilustrativas e reportagens que denotavam a necessidade de um ensino mais contextualizado para que os alunos sejam capazes de interpretar cientificamente situações presentes em seu cotidiano. Posteriormente, já na terceira etapa, as SEIs foram apresentadas como uma metodologia de ensino diferenciada, apta a ser trabalhada pelo professor em sala de aula com o intuito de promover a alfabetização científica dos educandos. Na última etapa os participantes foram orientados a responder o questionário final, que os indagava a respeito da utilização das SEIs em aulas e suas respectivas opiniões a respeito do minicurso.

A seguir, os resultados serão evidenciados e discutidos. Para facilitar a análise, os mesmos foram divididos em três partes: concepções prévias acerca do ensino investigativo e das SEIs; as características de um ensino adequado para ser implementado em sala de aula na concepção dos participantes dos minicursos; e, opinião dos participantes quanto a possível utilização da SEI em suas aulas. 


\section{CONCEPÇÕES PRÉVIAS ACERCA DO ENSINO INVESTIGATIVO E DAS SEIS}

No questionário inicial uma das perguntas interrogava os participantes acerca do que eles entendiam por ensino investigativo, tendo por objetivo conhecer as suas concepções prévias do assunto que seria trabalhado no MC. As repostas foram analisadas com base no capítulo 1 do livro "Ensino de Ciências por investigação" de autoria de Carvalho (2013) que esboça um referencial teórico destacando pontos importantes a serem inseridos e considerados em uma SEI, metodologia de ensino que condiz com um ensino investigativo, e nas concepções de Sasseron (s. d.) a respeito do ensino investigativo.

Para facilitar a análise das respostas obtidas nos dois minicursos aplicados, estas foram divididas em três classes:

a) Respostas mais relevantes, que se aproximam das concepções das autoras citadas acima que trabalham com o assunto;

b) Respostas corretas, mas que se apresentam de forma mais simples ou até mesmo incompleta;

c) Respostas que se apresentam como concepções a nível do senso comum ou até mesmo equivocadas em relação ao que foi questionado.

As respostas dos participantes do MC 1 foram classificadas da forma apresentada na tabela 1. Cada participante foi designado por um número aleatório para facilitar sua referência.

Tabela 1 - Classificação das respostas dos participantes do MC 1

\begin{tabular}{c|c|c|c|c}
\hline & $\begin{array}{c}\text { Respostas mais } \\
\text { relevantes }\end{array}$ & $\begin{array}{c}\text { Respostas corretas, porém } \\
\text { incompletas }\end{array}$ & $\begin{array}{c}\text { Respostas do senso } \\
\text { comum ou equivocadas }\end{array}$ & $\begin{array}{c}\text { Não } \\
\text { responderam }\end{array}$ \\
\hline MC 1 & 3,18 & $\begin{array}{c}4,5,7,8,9,10,16,17,20, \\
22,23,24\end{array}$ & $1,2,6,11,12,13,14,15$, & 21 \\
\hline $\begin{array}{c}\text { Valor em } \\
\text { percentagem }\end{array}$ & $8,3 \%$ & $50,0 \%$ & $37,5 \%$ & $4,2 \%$ \\
\hline
\end{tabular}

Fonte: Elaboração própria

Os participantes 3 e 18 tiveram suas respostas enquadradas como as mais relevantes, pois ao comentar sobre o ensino investigativo ressaltaram que este se baseia no uso de problematizações, além de trabalhar o conteúdo de uma forma mais contextualizada.

Carvalho (2013), ao apresentar as SEIs, comenta sobre a importância do problema para a construção do conhecimento, baseada em autores como Piaget, Bachelard e Vygotsky. Da mesma forma a autora ressalta que o trabalho com o conteúdo de maneira contextualizada é importante para que o aluno visualize a aplicação do conhecimento construído em sala de aula no seu cotidiano.

O participante 3 ainda comenta que no ensino investigativo o conhecimento prévio do estudante é valorizado:

"Uma metodologia de ensino que visa proporcionar a construção do conhecimento a partir de uma problematização inicial, a contextualização do conteúdo e a partir do conhecimento prévio do aluno.” (Transcrição da fala do participante 3).

Esta colocação condiz com a SEI, pois um de seus objetivos é proporcionar aos alunos condições de trazerem seus conhecimentos prévios para iniciar os novos.

As respostas mais relevantes foram assim classificadas, pois comentavam a respeito de pelo menos duas atividades-chave de uma SEI de acordo com Carvalho (2013), que neste caso foram, especificamente, o problema e a contextualização. 
Nas falas dos participantes 4, 5, 8, 16, 17, 22, 23 e 24 foi possível observar o destaque que deram ao problema e/ou a investigação para a abordagem do conteúdo. Já os participantes 7, 9 e 10 ressaltaram a utilização dos conhecimentos prévios dos estudantes como uma forma do professor conhecer o seu ambiente de ensino. O participante 20 desenvolveu sua resposta em torno da contextualização pois, segundo ele, esta faz com que os alunos participem de forma mais efetiva se enquadrando assim no ensino investigativo:

"Um ensino em que se baseia em contextualizar alguns temas, fazendo com que os alunos participem efetivamente, procurando sempre desenvolver o espírito investigativo dos educandos." (Transcrição da fala do participante 20).

A classificação das respostas acima como “corretas, porém incompletas” se deu desta forma, pois, ao comentar acerca do ensino investigativo, os participantes abordaram apenas uma das atividades-chave de uma SEI, sendo ora o problema, ora a contextualização. Apesar da utilização do conhecimento prévio dos educandos não ser especificamente uma atividade-chave da SEI, as respostas que citavam esse parâmetro também foram consideradas, pois como dito anteriormente, a utilização dos conhecimentos prévios para iniciar os novos é um dos objetivos da SEI proposta por Carvalho em 2013.

As respostas dos participantes 1, 2, 6, 12, 13, 14, 15 e 19 foram classificadas como "senso comum” pois além de não abordarem atividades-chave de uma SEI se deram de uma forma muito genérica podendo caracterizar outros tipos de ensino e não somente o investigativo. A resposta do participante 11 foi considerada equivocada pois o ensino investigativo é um método de ensino resultado de pesquisas anteriores e este não tem por objetivo desenvolver novos métodos, mas criar um ambiente investigativo para que os estudantes sejam conduzidos a um processo simplificado de trabalho científico com o intuito de irem pouco a pouco alcançando a alfabetização científica. (CARVALHO, 2013, p. 9).

"Ensino baseado em pesquisas para desenvolver métodos de ensino." (Transcrição da fala do participante 11).

Destaca-se que o participante 21 não relatou suas concepções prévias acerca do ensino investigativo.

As respostas dos participantes do MC 2 foram classificadas da mesma forma que as respostas dos participantes do MC 1, como apresentado na tabela a seguir.

Tabela 2 - Classificação das respostas dos participantes do MC 2

\begin{tabular}{c|c|c|c|c}
\hline & $\begin{array}{c}\text { Respostas mais } \\
\text { relevantes }\end{array}$ & $\begin{array}{c}\text { Respostas corretas, porém } \\
\text { incompletas }\end{array}$ & $\begin{array}{c}\text { Respostas do senso } \\
\text { comum ou } \\
\text { equivocadas }\end{array}$ & $\begin{array}{c}\text { Não } \\
\text { responderam }\end{array}$ \\
\hline MC 2 & $1,4,6,12$ & $\begin{array}{c}2,7,8,9,11,13,14,16,17, \\
18,19,20,22,24,25\end{array}$ & $3,5,10,15,21,23$ & - \\
\hline $\begin{array}{c}\text { Valor em } \\
\text { percentagem }\end{array}$ & $16,0 \%$ & $60,0 \%$ & $24,0 \%$ & $0,0 \%$ \\
\hline
\end{tabular}

Fonte: Elaboração própria

As respostas dos participantes 1, 4, 6, e 12 do MC 2 foram classificadas como mais relevantes pois, assim como a dos participantes 3 e 18 do MC 1, abordaram pelo menos duas atividades-chave de uma SEI. As atividades citadas pelos participantes do MC 2 coincidiram entre si e também coincidiram com as citadas pelos participantes do MC 1. Destacou-se mais uma vez a importância de uma problemática e da contextualização para que o ensino seja caracterizado como investigativo. 
"O ensino que desperta o olhar crítico, questionador e a reflexão do aluno. E que permite ao aluno um processo de ensino e aprendizagem mais autônomo, significativo e contextualizado." (Transcrição da fala do participante 6)

Os participantes $2,7,8,11,13,14,16,17,18,19,20,22$ e 25 apresentaram o problema e/ou a investigação como tópico principal em um ensino investigativo. Entretanto, por não abordarem outra atividade-chave de uma SEI suas respostas foram consideradas incompletas. Apenas o participante 17 citou a relação do ensino investigativo com a realidade do aluno, porém também o fez de forma sucinta, ainda não sendo considerada portanto como uma das respostas mais relevantes.

“Ensino voltado ao desenvolvimento de práticas de pesquisas para resolução de problemas da realidade.” (Transcrição da fala do participante 17)

Nenhum dos participantes deste MC citou a importância da valorização dos conhecimentos prévios dos alunos como uma característica do ensino investigativo. Ainda na fala do 11 e também dos participantes 9 e 24 observou-se o destaque para o papel mais ativo dos alunos no ensino investigativo, exercendo portanto um protagonismo maior no processo de aprendizagem.

"O processo onde o aluno é protagonista de seu aprendizado e busca responder/investigar a solução para um problema apresentado pelo professor." (Transcrição da fala do participante 11)

Conforme Sasseron (s. d.) no ensino por investigação o papel do professor se resume a orientador do trabalho, passando para os alunos o papel central que é a responsabilidade por sua aprendizagem.

Os participantes 3, 5, 10, 15, 21 e 23 apresentaram respostas a nível de senso comum para a questão. Nenhum deles citou atividades-chave de uma SEI, o que permite que suas respostas caracterizem não só o ensino investigativo, mas também outras abordagens de ensino.

"É uma proposta de ensino que faz o aluno pensar, refletir e buscar conhecimento" (Transcrição da fala do participante 23)

De modo geral, grande parte dos participantes dos minicursos citou o problema como característica principal do ensino investigativo. De acordo com Sasseron (s. d.) a proposição de um bom problema permite a construção de um ambiente investigativo. É interessante ressaltar que nenhum dos participantes citou a sistematização do conhecimento como característica do ensino investigativo, visto que esta também é atividade-chave de uma SEI. (CARVALHO, 2013).

Ao serem questionados especificamente a respeito das SEIs, observou-se que apenas $16,7 \%$ dos participantes do MC 1 afirmaram já terem ouvido falar sobre, enquanto que no MC 2 a percentagem foi significativamente maior, cerca de $60 \%$, mas ainda assim um tanto distante da totalidade. Com esses números percebeu-se que apesar da grande maioria dos participantes dos minicursos terem apresentado concepções corretas ao serem questionados a respeito do ensino investigativo, muitos não relacionaram a SEI com esse ensino, visto que esta é uma sequência didática (SD) que se enquadra nos parâmetros do mesmo.

Dos participantes do MC 1 que responderam a essa pergunta, observou-se que as suas respostas foram um tanto genéricas, pois não especificaram do que tratava essa metodologia de ensino ou quais seriam os seus pontos principais. O participante 1, por exemplo, apenas descreveu a sigla "SEI" por extenso. A resposta fornecida pelo participante 3 foi a mais completa, uma vez que destacou o objetivo da SEI na sua concepção.

É uma sequência didática investigativa objetivando a construção do conhecimento. (Transcrição da fala do participante 3) 
A maioria dos participantes do MC 2 respondeu a essa pergunta. Os participantes 12, 16, 18 e 24 apresentaram respostas mais simples, entretanto identificou-se nas falas dos participantes 3 e 22 o objetivo de uma SEI, que seria promover a alfabetização científica dos estudantes com o auxílio dos problemas. De acordo com Carvalho (2013) as SEIs foram propostas com intuito de criar um cenário investigativo no qual os alunos teriam a possibilidade de gradativamente serem alfabetizados cientificamente, ou seja, adquirindo aula a aula uma linguagem científica por meio do trabalho científico com os conteúdos. Apenas os participantes 6, 16, 17 e 21 não classificaram a SEI como uma metodologia problematizadora em suas falas, ao contrário dos demais que destacaram as problematizações como uma característica da SEI.

\section{AS CARACTERISTICAS DE UM ENSINO ADEQUADO PARA SER IMPLEMENTADO EM SALA DE AULA NA CONCEPÇÃO DOS PARTICIPANTES DOS MINICURSOS}

Os participantes dos dois minicursos foram questionados sobre quais seriam as características do ensino que eles consideravam adequado para ser trabalhado em sala de aula. A discussão será feita assumindo o ensino investigativo como o ideal a ser trabalhado em sala de aula, visto que o objetivo deste é promover a alfabetização científica dos estudantes. Portanto, as falas dos participantes serão analisadas de modo a comparar as características citadas pelos mesmos com as características de um ensino desejável, que segundo Garcia e Porlán (2000) é o modelo investigativo. O modelo investigativo na escola, também conhecido como modelos didáticos alternativos, se baseia no aperfeiçoamento do conhecimento com o objetivo de fazer com que os alunos tenham uma visão mais crítica e complexa da realidade, dando-lhes a oportunidade de uma participação mais responsável na sociedade.

Em relação ao MC 1, nas falas dos participantes 1, 3, 6, 7, 12, 14, 15, 16, 20 e 24 foi possível correlacionar as características citadas com as características de um ensino investigativo. Os participantes 1, 7, 12 e 16 destacaram a importância do papel ativo do aluno no processo de construção de conhecimento, enquanto que os participantes 14 e 15 destacaram a relevância de aproximar o conteúdo da realidade dos estudantes. Os participantes 3 e 20 evidenciaram tanto a importância do papel ativo do aluno na construção do seu conhecimento quanto a importância de trabalhar os conteúdos de forma contextualizada. Apenas os participantes 6 e 16 destacaram a importância da utilização de perguntas, questionamentos como características importantes em um ensino. Já o participante 24 destacou a relevância dos conhecimentos prévios dos alunos para o ensino. Todas as características citadas acima se enquadram em um ensino investigativo, todavia o número de participantes que incluíram essas características em suas respostas foi relativamente baixo. Os participantes 4, 10, 11, 13, 16, 18 e 23 destacaram a importância de métodos diferenciados nas aulas e/ou a utilização de recursos como experimentos, jogos e tecnologia como um auxílio para se alcançar o ensino adequado. As falas dos participantes 2, 5, 8, 9, 17 e 19 se resumiram a aulas mais interativas, dinâmicas e/ou didáticas, sendo estas, segundo eles, as características que um ensino ideal deve conter.

A grande maioria dos participantes do MC 2 citou características de um ensino ideal que coincidem com as características do ensino investigativo. Os participantes 6, 7, 13, 15, 19 e 21 destacaram a utilização de problematizações nas aulas; os participantes 2, 4, 5, 14, 17, 24 e também o 7 ressaltaram a importância de um ensino no qual o aluno desempenha uma postura mais ativa; os participantes 1, 2, 6, 10, 11, 12, 15, 16, 17, 19 e 25 destacaram a importância de considerar a realidade do estudante ao trabalhar com os conteúdos, se preocupando portanto com a contextualização. Apenas o participante 17 ressaltou a relevância da valorização dos conhecimentos prévios dos alunos no ensino. Todas as características citadas acima se enquadram em um ensino investigativo, onde foi possível identificar uma frequência maior dessas características nas falas dos participantes do MC 2 do que em comparação aos participantes do MC 1. Os participantes 8, 12 e 19 destacaram a utilização de recursos tecnológicos e/ou novos métodos como abordagens facilitadores do ensino. 


\section{OPINIÃO DOS PARTICIPANTES QUANTO A POSSÍVEL UTILIZACÃO DA SEI EM SUAS AULAS}

Ao final dos minicursos os participantes foram interrogados se, enquanto professores, utilizariam as SEIs em suas aulas e com qual frequência. Apenas um dos participantes do MC 1 afirmou que não utilizaria as SEIs em suas aulas, não justificando o motivo de sua resposta. Em contrapartida, todos os participantes do MC 2 afirmaram que utilizariam as SEIs em suas aulas. As respostas foram transcritas nos quadros 2 e 3 esboçados a seguir.

Quadro 2 - Resultados finais do MC 1

\begin{tabular}{|c|c|c|c|}
\hline \multicolumn{4}{|c|}{ MC 1} \\
\hline \multirow[b]{2}{*}{ Participantes } & \multicolumn{3}{|c|}{ Respostas transcritas } \\
\hline & $\begin{array}{l}\text { Você utilizaria as } \\
\text { SEIs nas suas aulas? }\end{array}$ & Justificativa & $\begin{array}{l}\text { Frequência da } \\
\text { utilização }\end{array}$ \\
\hline 1 & Sim & $\begin{array}{l}\text { Pois com a participação dos alunos no processo } \\
\text { promovem uma aprendizagem significativa. }\end{array}$ & \\
\hline 2 & Sim & $\begin{array}{c}{[\ldots] \text { para sempre ser bem dinâmico e não intediar }} \\
\text { os alunos. }\end{array}$ & $\begin{array}{l}\text { Após todo término ou } \\
\text { começo da matéria }\end{array}$ \\
\hline 3 & Sim & & $\begin{array}{c}\text { A frequência iria } \\
\text { depender do } \\
\text { conteúdo. Pois a aula } \\
\text { acabada sendo mais } \\
\text { demorada. }\end{array}$ \\
\hline 4 & Com certeza. & $\begin{array}{c}\text { Pois acredito que uma forma de motivar os alunos } \\
\text { a aprender e se interessar mais pelo conteúdo. }\end{array}$ & \\
\hline 5 & Sim & $\begin{array}{c}\text { Utilizaria, pois a SEI é uma forma de construção } \\
\text { de conhecimento que mais tem chances de } \\
\text { estimular a curiosidade e interesse do aluno. }\end{array}$ & $\begin{array}{l}\text { Utilizaria com uma } \\
\text { frequência de dois } \\
\text { vezes durante o mês. }\end{array}$ \\
\hline 6 & Sim & $\begin{array}{c}\text { Porque é uma forma de trazer o aluno para } \\
\text { entender que nem tudo é sempre como o professor } \\
\text { diz fazê-lo entender que ele pode desenvolver o } \\
\text { seu próprio conhecimento. }\end{array}$ & \\
\hline 7 & Sim & $\begin{array}{c}\text { Pois traria o aluno p/ mais perto dos } \\
\text { conhecimentos científicos sem ser algo mecânico. }\end{array}$ & \\
\hline 8 & Sim & $\begin{array}{c}\text { Porque as SEIs permite trazer o aluno a se } \\
\text { interessar pela matéria sem ser por massivas aulas } \\
\text { que só apresentam conteúdos. }\end{array}$ & $\begin{array}{l}\text { Pelo menos uma vez } \\
\text { por bimestre. }\end{array}$ \\
\hline 9 & Sim & $\begin{array}{l}\text { Porque leva o aluno a aprender a pensar mais } \\
\text { sobre os temas estudados e também a ter mais } \\
\text { curiosidade a repassar aquele conteúdo. }\end{array}$ & \\
\hline 10 & Sim & $\begin{array}{c}\text { Pois a utilização das SEIs ajudaria a tornar a aula } \\
\text { mais participativa, e diante disso mais interessante } \\
\text { para o aluno. }\end{array}$ & \\
\hline 11 & Sim & $\begin{array}{c}\text { Porque é uma forma de sair da rotina, até porque } \\
\text { só utilizar uma aula expositiva, os alunos ficam } \\
\text { desmotivados, com esse método eles poderiam se } \\
\text { interessar mais pelo conteúdo. }\end{array}$ & \\
\hline
\end{tabular}




\begin{tabular}{|c|c|c|c|}
\hline \multicolumn{4}{|c|}{ MC 1} \\
\hline \multirow[b]{2}{*}{ Participantes } & \multicolumn{3}{|c|}{ Respostas transcritas } \\
\hline & $\begin{array}{l}\text { Você utilizaria as } \\
\text { SEIs nas suas aulas? }\end{array}$ & Justificativa & $\begin{array}{c}\text { Frequência da } \\
\text { utilização }\end{array}$ \\
\hline 12 & Sim & $\begin{array}{c}\text { Pois teria uma melhor sistematização do } \\
\text { conhecimento contextualizando-o e possivelmente } \\
\text { seria possível obter melhores resultados em } \\
\text { relação a aquisição de conhecimento. }\end{array}$ & $\begin{array}{c}\text { Eventualmente, pois é } \\
\text { uma metodologia } \\
\text { trabalhosa. }\end{array}$ \\
\hline 13 & Não & & \\
\hline 14 & Sim & $\begin{array}{c}\text { Porque o método proporciona a construção do } \\
\text { conhecimento, havendo interação entre os alunos. }\end{array}$ & $\begin{array}{c}\text { Pelo menos } 1 \text { vez no } \\
\text { mês. }\end{array}$ \\
\hline 15 & Sim & $\begin{array}{c}\text { Utilizaria pois aproximaria os conteúdos aplicados } \\
\text { à realidade dos alunos, facilitando seu } \\
\text { aprendizado. }\end{array}$ & $\begin{array}{c}\text { Aplicaria pelo menos } \\
\text { uma vez ao mês. }\end{array}$ \\
\hline 16 & Sim & $\begin{array}{l}\text { Porque é uma ótima metodologia de aprendizado } \\
\text { para os alunos. }\end{array}$ & $\begin{array}{c}\text { Pelo menos } 1 \text { vez por } \\
\text { semestre. }\end{array}$ \\
\hline 17 & Sim & $\begin{array}{c}\text { Porque é uma forma de envolver e estimular os } \\
\text { alunos, e romper um pouco com as aulas } \\
\text { tradicionais. }\end{array}$ & Eventualmente. \\
\hline 18 & Sim & $\begin{array}{l}\text { Pois é uma forma de existir uma maior interação } \\
\text { entre o professor e aluno. }\end{array}$ & \begin{tabular}{|c|} 
Tentaria utilizá-lo 2 \\
ou 3 vezes no mês, de \\
acordo com a \\
disponibilidade. \\
\end{tabular} \\
\hline 19 & Sim & $\begin{array}{l}\text { Pois é uma forma de interação entre docente- } \\
\text { discente e uma maneira de ter conhecimento sobre } \\
\text { o aprendizado dos discentes, o foco das SEIs está } \\
\text { no aprendizado e isso que é primordial na } \\
\text { educação. }\end{array}$ & $\begin{array}{c}\text { A frequência poderia } \\
\text { ser uma vez ao mês, } \\
\text { pois para esse método } \\
\text { o tempo é muito } \\
\text { curto. }\end{array}$ \\
\hline 20 & Sim & $\begin{array}{c}\text { Porém deverá ser planejado com muito cuidado, } \\
\text { pensando sempre no planejamento ideal. }\end{array}$ & $\begin{array}{c}\text { Dependendo do tema } \\
1 \text { vez por semestre. }\end{array}$ \\
\hline 21 & Sim & $\begin{array}{c}\text { Pois é um método bom, mas demanda bastante } \\
\text { tempo para elaborar quanto para aplicar ainda mais } \\
\text { em uma sala com } 20 \text { ou } 30 \text { alunos mas que é bom } \\
\text { sem dúvida. }\end{array}$ & $\begin{array}{l}\text { Seria aplicado pelo } \\
\text { menos uma vez no } \\
\text { mês. }\end{array}$ \\
\hline 22 & Sim & $\begin{array}{l}\text { Porque os alunos aprendem melhor se tivessem } \\
\text { contextualização. }\end{array}$ & 2 vezes por semestre. \\
\hline 23 & Sim & $\begin{array}{c}\text { Acho importante fazer aulas especiais usando } \\
\text { metodologias diferentes para atrair a atenção dos } \\
\text { alunos e melhorar a qualidade do ensino. }\end{array}$ & \\
\hline 24 & Sim & $\begin{array}{c}\text { Porque é bem interessante parece ser eficaz no } \\
\text { aprendizado. }\end{array}$ & $\begin{array}{c}\text { Tentaria utilizar no } \\
\text { mínimo uma vez por } \\
\text { bimestre e } \\
\text { principalmente } \\
\text { abordando conteúdos } \\
\text { mais difíceis para } \\
\text { aprendizado do aluno. }\end{array}$ \\
\hline
\end{tabular}


A justificativas para a utilização das SEIs nos participantes do MC 1 giraram em torno do fato de que este método de ensino torna a aula mais participativa, despertando portanto o interesse dos discentes com a finalidade de facilitar o processo de ensino e aprendizagem. Todavia, alguns participantes destacaram a dificuldade de utilizar esta metodologia de ensino com frequência pelo fato de ter considerado a mesma como "trabalhosa", como apurado na fala do participante 12.

Quadro 3 - Resultados finais do MC 2

\begin{tabular}{|c|c|c|c|}
\hline \multicolumn{4}{|c|}{ MC 2} \\
\hline \multirow[b]{2}{*}{ Participantes } & \multicolumn{3}{|c|}{ Respostas transcritas } \\
\hline & $\begin{array}{c}\text { Você utilizaria as SEIs } \\
\text { nas suas aulas? }\end{array}$ & Justificativa & Frequência da utilização \\
\hline 1 & Sim & & $\begin{array}{c}\text { Utilizaria sempre que } \\
\text { conseguisse adequar o } \\
\text { tema a problematização } \\
\text { estruturada como a } \\
\text { metodologia sugere. }\end{array}$ \\
\hline 2 & Sim & $\begin{array}{c}\text { Apesar de encontrar algumas dificuldades em } \\
\text { abordar problemas científicos na minha } \\
\text { disciplina, tentaria trazer os problemas sociais } \\
\text { para essa metodologia, porque isso geraria um } \\
\text { debate a fim de enriquecer o conhecimento. }\end{array}$ & Uma vez a cada bimestre. \\
\hline 3 & Sim & $\begin{array}{c}\text { Enquanto trabalhadora do ensino não-formal, } \\
\text { já utilizo ensino baseado em problemas, mas } \\
\text { não a SEI. Acredito que para o público que } \\
\text { trabalho essa sequência precisaria ser adaptada, } \\
\text { mas no ensino formal seria melhor aplicado. }\end{array}$ & $\begin{array}{l}\text { Não sei informar a } \\
\text { frequência. }\end{array}$ \\
\hline 4 & Sim & $\begin{array}{c}\text { Pois trata-se de uma forma de tornar a } \\
\text { aprendizagem mais ativa. }\end{array}$ & $\begin{array}{l}\text { Sempre que possível, } \\
\text { levando em conta o } \\
\text { tempo para a preparação } \\
\text { das aulas, a estrutura } \\
\text { disponível, etc. } \\
\end{array}$ \\
\hline 5 & Sim & $\begin{array}{c}\text { Acho uma abordagem interessante, porém sua } \\
\text { utilização pode ser complicada, dependendo do } \\
\text { tema que será abordado. Mas acredito ser } \\
\text { possível utilizar a SEI na sala de aula para } \\
\text { tornar as aulas mais atrativas e fazer com que } \\
\text { os alunos participem ativamente das mesmas. }\end{array}$ & $\begin{array}{l}\text { A frequência dependerá } \\
\text { do assunto abordado. }\end{array}$ \\
\hline 6 & Sim & & $\begin{array}{l}\text { Utilizaria se possível, } \\
\text { uma vez no bimestre } \\
\text { como introdução ao } \\
\text { conteúdo, mas devido sua } \\
\text { complexidades estrutural, } \\
\text { poderia utilizar ao menos } \\
\text { uma vez ou duas no ano. }\end{array}$ \\
\hline 7 & Sim & $\begin{array}{c}\text { Pois é uma metodologia que permite a } \\
\text { participação dos alunos, motivando a busca do } \\
\text { conhecimento. }\end{array}$ & $\begin{array}{l}\text { Se possível uma vez no } \\
\text { bimestre. }\end{array}$ \\
\hline 8 & Sim & $\begin{array}{l}\text { Trabalho em grupo leva o aluno a uma } \\
\text { aprendizagem colaborativa tornando-a mais }\end{array}$ & \\
\hline
\end{tabular}




\begin{tabular}{|c|c|c|c|}
\hline \multicolumn{4}{|c|}{ MC 2} \\
\hline \multirow[b]{2}{*}{ Participantes } & \multicolumn{3}{|c|}{ Respostas transcritas } \\
\hline & $\begin{array}{c}\text { Você utilizaria as SEIs } \\
\text { nas suas aulas? }\end{array}$ & Justificativa & Frequência da utilização \\
\hline & & atrativa e significativa. & \\
\hline 9 & Sim & & \\
\hline 10 & Sim & & Uma vez por bimestre. \\
\hline 11 & Sim & $\begin{array}{c}\text { As SEIs são viáveis para uso frequente pois o } \\
\text { professor pode adequá-la ao tempo didático } \\
\text { disponível para determinado conteúdo. }\end{array}$ & Talvez 2 por semestre. \\
\hline 12 & Sim & & $\begin{array}{c}\text { Sempre que o conteúdo } \\
\text { permitir. }\end{array}$ \\
\hline 13 & Sim & $\begin{array}{c}\text { Porque considero uma abordagem interessante } \\
\text { que terá muito a contribuir para o ensino } \\
\text { discente. }\end{array}$ & $\begin{array}{c}\text { Seria utilizada uma vez } \\
\text { por bimestre, devido ao } \\
\text { tempo ocupado para } \\
\text { aplicação. }\end{array}$ \\
\hline 14 & Sim & & Já utilizo com frequência. \\
\hline 15 & Sim & \begin{tabular}{|c|} 
A metodologia possibilita aulas mais \\
dinâmicas, tornando os alunos como centro do \\
processo de ensino e possibilitando a \\
contextualização dos conteúdos no meio social.
\end{tabular} & \\
\hline 16 & Sim & $\begin{array}{c}\text { Acredito ser uma metodologia que contribui } \\
\text { para um aprendizado significativo. }\end{array}$ & \\
\hline 17 & Sim & & $\begin{array}{l}\text { Sempre como ponto de } \\
\text { partida para abordar um } \\
\text { conteúdo. }\end{array}$ \\
\hline 18 & Sim & $\begin{array}{l}\text { Entendo que metodologias que conduzem o } \\
\text { aluno a problematização e que fuja da forma } \\
\text { tradicional de ensino é bem-vinda. }\end{array}$ & $\begin{array}{c}\text { Utilizaria para inserir um } \\
\text { novo conteúdo. }\end{array}$ \\
\hline 19 & Sim & $\begin{array}{c}\text { Pois as sequências investigativas contribuem } \\
\text { significativamente para a construção do } \\
\text { conhecimento. }\end{array}$ & \\
\hline 20 & Sim & & $\begin{array}{l}\text { Pelo menos uma vez a } \\
\text { cada etapa de ensino } \\
\text { (bimestre, trimestre ou } \\
\text { semestre). }\end{array}$ \\
\hline 21 & Sim & $\begin{array}{c}\text { Pois o ensino se torna mais dinâmico e atrativo } \\
\text { para o aluno, facilitando as práticas } \\
\text { pedagógicas. }\end{array}$ & \\
\hline 22 & Sim & $\begin{array}{c}\text { Porque é uma forma de promover o interesse } \\
\text { dos alunos nas aulas, trabalhando de formas } \\
\text { dinâmicas. }\end{array}$ & $\begin{array}{l}\text { Sempre ao iniciar um } \\
\text { tema novo para poder } \\
\text { trabalhar com a SEI ao } \\
\text { longo das aulas do } \\
\text { bimestre. }\end{array}$ \\
\hline 23 & Sim & $\begin{array}{c}\text { Pois parece ser um método interessante e terem } \\
\text { sido apresentados resultados positivos. }\end{array}$ & \\
\hline 24 & Sim & $\begin{array}{l}\text { Pois é uma maneira do aluno desenvolver o } \\
\text { conhecimento aplicado por meio da }\end{array}$ & $2 \mathrm{X}$ por bimestre. \\
\hline
\end{tabular}




\begin{tabular}{|c|c|c|c|}
\hline \multirow{2}{*}{ Participantes } & \multicolumn{3}{|c|}{ MC 2 } \\
\cline { 2 - 4 } & $\begin{array}{c}\text { Você utilizaria as SEIs } \\
\text { nas suas aulas? }\end{array}$ & Justificativa & Frequência da utilização \\
\hline & Sim & problematização. & Utilizaria 3X ao ano. \\
\hline 25 & Porque leva o aluno a reflexão. & \\
\hline
\end{tabular}

Fonte: Elaboração própria

As justificativas apresentadas pelos participantes do MC 2 se resumem a utilização da metodologia como facilitadora do processo de construção do conhecimento, visto que ao possibilitar a participação ativa dos alunos torna as aulas mais atrativas. Também foi possível identificar na fala do participante 13 uma ressalva em relação a utilização da metodologia devido o tempo que ela ocupa para ser aplicada. É interessante ressaltar que o participante 14 destacou que já utiliza essa metodologia em suas aulas.

Nas justificativas dos participantes 2 e 3 eles destacaram a adaptação que teriam que fazer enquanto professores para trabalhar esta metodologia em suas aulas. Devido a maioria das aplicações desta metodologia estar voltada para o âmbito das Ciências Naturais, eles sendo professores de outras áreas encontrariam dificuldades na escolha do problema, que não seria um problema científico. Todavia, o participante 2 destacou que inserindo problemas sociais ao invés de problemas científicos, ele conseguiria levantar uma discussão para enriquecimento do conhecimento.

\section{CONSIDERAÇÕES FINAIS}

Este trabalho teve por objetivo discutir três aspectos relacionados aos resultados coletados antes e após a aplicação de dois minicursos: i) conhecimentos prévios dos participantes em relação ao ensino investigativo e, especificamente às SEIs; ii) as características de um ensino adequado na opinião dos participantes; iii) o questionamento quanto à possível utilização das SEIs em aulas ministradas futuramente pelos próprios participantes.

$\mathrm{Na}$ análise dos resultados obtidos por meio do questionário inicial foi possível evidenciar diferenças em relação ao perfil dos participantes dos dois minicursos. Quanto às concepções prévias do ensino investigativo verificou-se um número maior de respostas corretas e mais relevantes nos questionários dos participantes do MC 2. Da mesma forma, a maioria desses participantes tinham concepções prévias mais elaboradas em relação as SEIs do que em comparação aos participantes do MC 1. Também foi possível correlacionar de forma mais efetiva as características de um ensino ideal com as características do ensino investigativo nas falas dos participantes do MC 2. Todos estes resultados reafirmam as diferenças em relação ao perfil dos participantes, que no MC 2, em sua maioria, já eram professores formados e atuantes, demonstrando assim uma facilidade maior para o fornecimento de respostas mais completas e elaboradas requeridas no questionário.

Uma percentagem elevada de participantes, ainda que superior no MC 1, mas também significativa no MC 2, nunca tinham ouvido falar sobre as SEIs. Esta percepção pode ser atribuída ao fato de que essa metodologia de ensino só foi publicada oficialmente em livro no ano de 2013, sendo considerada, portanto, nova e com poucos trabalhos publicados. No mesmo sentido, uma percentagem significativa de participantes dos dois minicursos apresentaram respostas equivocadas ou de senso comum quando questionados a respeito do que eles entendiam por ensino investigativo.

Ainda que de forma subjetiva, ao serem questionados sobre as características de um ensino ideal, grande parte dos participantes citaram características que coincidem com os aspectos do ensino 
investigativo, coincidindo com as concepções dos autores Garcia e Porlán (2000) que consideram o modelo investigativo como o modelo de ensino desejável a ser implementado em salas de aula.

Nos resultados finais, considerando os dois minicursos, foi possível averiguar que $98 \%$ dos participantes afirmaram que utilizariam as SEIs em suas aulas. As justificativas apresentadas pelos participantes para esta afirmação se basearam na constatação que os mesmos fizeram de que o modelo investigativo possui características que favorecem o processo de construção do conhecimento. Um dos participantes destacou que pretende trabalhar com a SEI ainda que seja necessário fazer algumas adaptações devido a algumas particularidades que a SEI possui voltadas para o Ensino de Ciências, que nesse caso seria a utilização de problemas científicos. Esse participante destacou que pretende fazer uso das SEIs, mas utilizando problemas sociais.

Conhecer os concepções prévias dos professores em relação a determinado assunto que será discutido e analisá-las é um trabalho importante, pois nos revela o grau de instrução dos participantes, nesse caso em relação ao modelo de ensino apresentado, permitindo a comparação com os resultados finais e percepção dos impactos produzidos pela ação executada. No minicurso em questão, a discussão acerca do ensino tradicional e do modelo de ensino investigativo permitiu que professores que nunca tiveram contato com as SEIs demonstrassem interesse de utilizá-las em suas aulas a partir daquele momento.

Diante dos resultados obtidos, pôde-se constatar que as quatro horas utilizadas no minicurso foram suficientes para iniciar uma discussão sobre o modelo de ensino tradicional e apresentar a SEI dentro dos parâmetros do modelo de ensino desejável, trazendo desta forma uma contribuição positiva na formação inicial e continuada dos professores participantes. A participação de minicursos como o descrito neste trabalho, é de extrema importância para o professor, seja em formação inicial ou continuada, buscar o contínuo aprimoramento de sua prática docente e reconhecer a importância do seu papel, enquanto orientador e mediador do processo de aprendizagem.

\section{REFERENCIAS}

ALBERGARIA, D. Pensando criticamente as novas abordagens de ensino. ComCiência [online], Campinas, s/v. n. 115, s. p., 2010.

AZEVEDO, M. C. P. S. Ensino por investigação: problematizando as atividades em sala de aula. In.: CARVAlHO, A. M. P. (org.). Ensino de Ciências: unindo a pesquisa e a prática. São Paulo: Thomson, 2004. p. 19-33.

CARVALHO, A. M. P. (org.). Ensino de Ciências por Investigação. São Paulo: Cengage Learning, 2013.

DELIZOICOV, D. ; ANGOTTI, J. A.; PERNAMBUCO, M. M. Ensino de Ciências: fundamentos e métodos. São Paulo: Cortez, 2007.

ECHEVERRÍA, M. D. P. P; POZO, J. I. Aprender a resolver problemas e resolver problemas para aprender. In.: POZO, J. I. (org.). A solução de problemas. Porto Alegre: Artmed, 1998. p. 13-42.

GARCIA, J. E.; PORLÁN, R. Teoria e prática na ação docente. Caderno Pedagógico, Lajeado, v. 1, n. 3, p. 7-42, set./dez. 2000.

GATTI, B. A. Formação de professores: condições e problemas atuais. Revista Internacional de Formação de Professores (RIFP), Itapetininga, v. 1, n. 2, p. 161-171, abr./jun. 2016.

GERHARDT, T. E.; SILVEIRA, D. T. (org.) Métodos de pesquisa. Porto Alegre: UFRGS, 2009.

GUIMARÃES, G. M. A.; ECHEVERRÍA, A. R.; MORAES, I. J. Modelos didáticos no discurso de professores de ciências. Investigações em Ensino de Ciências, v. 11, n. 3, p. 303-322, set./dez. 2006. 
IMBERNÓN, F. Qualidade do ensino e formação do professorado: uma mudança necessária. São Paulo: Cortez, 2016.

IMBERNÓN, F. Formação docente e profissional: formar-se para a mudança e a incerteza. São Paulo: Cortez, 2009.

KRASILCHIK, M. Ensino de Ciências e a formação do cidadão. Em Aberto, Brasília, v. 7, n. 40, out./dez. 1988.

MALDANER, O. A. A formação inicial e continuada de professores de química: professor/pesquisador. Ijuí: Unijuí, 2003.

MASETTO, M. T. Mediação pedagógica e o uso da tecnologia. In.: MORAN, J. M.; MASETTO, M. T.; BEHRENS, I. A. (org.). Novas tecnologias e mediação pedagógica. Campinas: Papirus, 2000. p. 67-132.

MOREIRA, M. A. Pesquisa em ensino: métodos qualitativos e quantitativos. Porto Alegre: UFRGS, 2009.

PORLÁN, R.; RIVERO, A. El conocimiento de los profesores: uma proposta em el área de ciencias. Sevilha: Diáda, 1998.

SASSERON, L. H., CARVALHO, A. M. P. Almejando a alfabetização cientifica no ensino fundamental: a proposição e a procura de indicadores do processo. Investigações em Ensino de Ciências, Porto Alegre, v. 13, n. 3, p. 333-352, set./dez. 2008.

SASSERON, L. H. Ensino por investigação: pressupostos e práticas. São Paulo, s. d. (Apostila de Licenciatura em Ciências USP/Univesp. Módulo 7. Capítulo 12. p. 116-124). Disponível em: https://midia.atp.usp.br/plc/plc0704/impressos/plc0704_12.pdf. Acesso em: 13 maio 2018.

SASSERON, L. H.; MACHADO V. F. Alfabetização científica na prática: inovando a forma de ensinar Física. São Paulo: Livraria de Física, 2017.

SOLÍS, E. et al. Las concepciones de los profesores de ciências de secundaria em formación inicial sobre metodologia de enseñanza. Revista Española de pedagogia, Madrid, v. 70, n. 253, p. 495 - 514, sep./dic. 2012. 